\title{
Uma análise sobre o processo de ensino pedagógico e a inserção da alimentação saudável na educação infantil
}

\author{
An analysis of the pedagogical teaching process and the insertion of healthy eating in early \\ childhood education \\ Un análisis del proceso de enseñanza pedagógica y la inserción de la alimentación saludable en la \\ educación infantil
}

Recebido: 29/11/2021 | Revisado: 03/12/2021 | Aceito: 25/01/2022 | Publicado: 28/01/2022

Hellita do Nascimento Fernandes ORCID: https://orcid.org/0000-0002-8212-7165 Universidade Federal de Campina Grande, Brasil E-mail: hellitanascimento2@gmail.com Raquel Formiga de Medeiros ${ }^{1}$ ORCID: https://orcid.org/0000-0002-1198-5015 Universidad del Museo Social Argentino, Argentina E-mail: raquelfdm@hotmail.com Agílio Tomaz Marques

ORCID: https://orcid.org/0000-0001-8364-5063 Universidade Federal de Campina Grande, Brasil E-mail: agiliotomaz@hotmail.com

Hugo Sarmento Gadelha ${ }^{2}$

ORCID: https://orcid.org/0000-0001-9414-0554 Universidad del Museo Social Argentino, Argentina E-mail: hugoscurso@uol.com.br

Hiran Mendes Castro Filho ${ }^{3}$

ORCID: https://orcid.org/0000-0002-1418-159X Universidad del Museo Social Argentino, Argentina E-mail: hirancastro@gmail.com

Suzana Araújo dos Santos

ORCID: https://orcid.org/0000-0001-5955-9421

Universidade Federal de Campina Grande, Brasil E-mail: suzana.santos2007@yahoo.com.br

Matheus Matos Ferreira Silva

ORCID: https://orcid.org/0000-0002-3905-1951

Universidade Federal de Campina Grande, Brasil

E-mail: matheusmatosfs@gmail.com Adryele Gomes Maia

ORCID: https://orcid.org/0000-0002-7433-7138 Universidade Federal do Rio Grande do Norte, Brasil E-mail: adryelegm@gmail.com

\begin{abstract}
Resumo
Esse artigo tem como objetivo analisar como está sendo efetivado o direito constitucional à alimentação no contexto da a educação alimentar, que deve ser iniciada na infância, no período o qual o hábito alimentar é formado. Visto que a escola desempenha um papel de importante função na formação do hábito alimentar e que nesse ambiente as crianças permanecem por um expressivo período de tempo, pode ser considerada um local para a intervenção na busca de um estilo de vida mais saudável. Desse modo, para melhor compreensão, esse estudo será realizado a luz das teorias de Alessandra Jesus, que por sua vez explicita que com base na coleta dos dados observados e atividades práticas abordadas, é posto em vista que, o lúdico em sala de aula, se faz necessário principalmente na educação infantil, em que o desenvolvimento escolar começa através do brincar. Nesta senda, aprender brincando de forma satisfatória é trivial para fomentar a alimentação infantil.
\end{abstract}

Palavras-chave: Criança; Lúdico; Ensino; Aprendizagem; Alimento.

\footnotetext{
${ }^{1}$ Doutorando pela Universidad del Museo Social Argentino.

${ }^{2}$ Doutorando pela Universidad del Museo Social Argentino.

${ }^{3}$ Doutorando pela Universidad del Museo Social Argentino.
} 


\begin{abstract}
This article aims to analyze how the constitutional right to food is being implemented in the context of food education, which must be started in childhood, in the period in which the eating habit is formed. Since the school plays an important role in the formation of eating habits and that children remain in this environment for an expressive period of time, it can be considered a place for intervention in the search for a healthier lifestyle. Thus, for a better understanding, this study will be carried out in the light of the theories of Alessandra Jesus, who in turn explains that based on the collection of observed data and practical activities addressed, it is put in view that, the playful in the classroom, it is necessary mainly in early childhood education, in which school development begins through playing. In this path, learning through play in a satisfactory way is trivial to promote infant feeding.
\end{abstract}

Keywords: Kid; Ludic; Teaching; Learning; Food.

\title{
Resumen
}

Este artículo tiene como objetivo analizar cómo se está implementando el derecho constitucional a la alimentación en el contexto de la educación alimentaria, que debe iniciarse en la infancia, en el período en que se forma el hábito alimentario. Dado que la escuela juega un papel importante en la formación de hábitos alimentarios y que los niños permanecen en ese ambiente por un tiempo expresivo, puede ser considerada un lugar de intervención en la búsqueda de un estilo de vida más saludable. Así, para una mejor comprensión, este estudio se realizará a la luz de las teorías de Alessandra Jesús, quien a su vez explica que a partir de la recopilación de datos observados y actividades prácticas abordadas, se pone de manifiesto que, lo lúdico en el aula, es necesario principalmente en la educación infantil, en la que el desarrollo escolar comienza a través del juego. En este camino, aprender jugando de manera satisfactoria es trivial para promover la alimentación infantil.

Palabras clave: Niño; Lúdico; Enseñando; Aprendiendo; Alimentación.

\section{Introdução}

Educar faz parte de um conjunto de atribuições pedagógicas as quais perpassam por alguns processos. Para efetivação desse processo, necessitamos revisar o Projeto Político-Pedagógico (PPP), pois nossos princípios permeiam a esse projeto para um caminho de ensino e qualidade.

Propondo-se que o planejamento escolar norteia-se a essa perspectiva, é valido ressaltarmos que, Com o surgimento de novas propostas pedagógicas, o planejamento e o currículo sofrem influência. De acordo com Sayão e Muniz o planejamento está diretamente ligado ao tipo de homem e sociedade que queremos formar. Claro que o mesmo tem sua finalidade funcionalista, em que define estratégias e antecipa imprevisto. Mas deve ser compreendido acima de tudo como um instrumento de formação de homem e sociedade. (Da Silva et al., 2016, p. 1/17)

Desse modo, o planejamento tornou-se a ferramenta principal para o desenvolvimento do trabalho profissional, é a partir dele que podemos estruturar e alinhar todos os conhecimentos no âmbito educacional. É de suma importância entender o quanto que o planejamento pedagógico é importante no organizar das atividades assim como dos conteúdos trabalhados na escola.

Essa organização dos pensamentos se dá na perspectiva de melhoria dos processos de ensino e aprendizagem das nossas crianças. Portanto, De acordo com Silva (2016, p. 17),

Nessa ótica, o quê planejar, porquê planejar e como planejar a atividade docente tornam-se preponderantes para tomar as decisões pedagógicas sobre as quais os docentes estão sujeitos. Sendo assim, é necessário planejar de maneira intencional essa prática. Nessa ótica, o planejamento de aula não se resume ao um plano fechado e pré-estruturado. Na verdade, ele é um processo que está em movimento entre o pensado e o vivido.

Conforme o exposto, o planejamento é uma das formas de organizar as atividades pedagógicas, assim como antecipar obstáculos e antever ações, é através desse cuidado que existe a necessidade de estabelecer objetivos e metas na Instituição.

Embora tenhamos algumas dificuldades em relação à preparação desse plano pedagógico, é sempre valido ressaltarmos que é através da equipe em conjunto que se faz o desenvolver essas atividades. Pois, entende-se que, é de fundamental importância uma equipe a qual trabalhe atrelada a um mesmo objetivo, com uma boa interação, as quais busquem 
eficácia para o desenvolvimento da equipe em sua totalidade. Almejando o melhor para as escolas e nossos alunos.

Desta feita, esse estudo pretende colaborar com pesquisas relacionadas à educação e a fomentação à alimentação infantil, servindo de fonte de pesquisa para trabalhos futuros que versem sobre a efetivação de direitos dos apenados do sistema prisional brasileiro.

\section{Desenvolvimento}

A Aprendizagem significativa, se caracteriza por meio da vivência e da prática cotidiana do aluno, desenvolvendo-o em um ser pensante, crítico e criativo nas tomadas de decisões, melhorando assim a sua integração e construção individual e social.

É através do trabalho desenvolvido cotidianamente nas escolas, seu objetivo é a responsabilidade com a aprendizagem e desenvolvimento integral dos indivíduos, o qual traça propósitos alcançáveis num plano estratégico anual.

Esses planejamentos pedagógicos são realizados semanais/quinzenais por toda equipe, mediante a isso, traçam-se metas que atendam e realizem as propostas discutidas, pois posteriormente, as mesmas serão desenvolvidas e trabalhadas num determinado período e/ou a cada ano.

Consequentemente, com base no PPP que planejamento norteia o ano letivo e a prática pedagógica destinada à implementação do ensino se dá através da BNCC e as Orientações próprias do Sistema de Ensino adotado pela escola, de modo que as habilidades contempladas sejam desenvolvidas a cada ano/série com seriedade e sem nenhum prejuízo para os alunos, tendo como base o que é pertinente a faixa etária de cada série e segmentos.

O objetivo da escola norteia-se em promover educação de qualidade para todos os alunos, levando-os a construir sua história com proatividade, responsabilidade, dignidade e autonomia, contribuindo para uma sociedade mais justa, fraterna e feliz.

Ademais, algumas ações pautam-se no desenvolvimento do trabalho em equipe, assim como; buscar ter o conhecimento de todo o trabalho desenvolvido dentro do ambiente escolar, indissociável entre teoria e prática; ser democrático e justo para com todos; permanecer presente e participativo perante a instituição, bem como, ser responsável pelo desenvolvimento integral dos cidadãos; e desenvolver a tríade AÇÃO/REFLEXÃO/AÇÃO.

Contudo, algumas ações do Projeto Político Pedagógico que são transformadas em ação durante o ano letivo, com experiências exitosas, se dão por meio de projetos diversos que estimulam a criatividade e desenvolvimento de habilidades e talentos dos nossos alunos, como a ArtCulAção, uma atividade a qual possibilita o aluno desenvolver seus gestos e movimentos, ao mesmo tempo, permite que o aluno descubra a importância de uma alimentação saudável.

Nessa perspectiva, a educação alimentar, que deve ser iniciada na infância, no período o qual o hábito alimentar é formado. Para iniciarmos a discursão acerca da inserção da ludicidade como recurso para uma alimentação saudável, faz-se necessário ressaltarmos o quanto é fundamental estimular não só a ludicidade assim como uma alimentação saudável e permanente. Diante desse contexto, entende-se que a educação alimentar é também um fator primordial para o desenvolvimento da criança, é valido explanarmos que a escola desempenha um papel o qual vai para além dos princípios pedagógicos.

O hábito alimentar se faz presente no cotidiano dos nossos dias e das nossas atividades, compreendendo que as crianças passam um expressivo período de tempo nas instituições de ensino, o hábito alimentar a princípio, se efetiva em âmbitos escolares.

Desse modo, para melhor compreensão, esse estudo será realizado a luz das teorias de Alessandra Jesus, que por sua vez explicita que com base na coleta dos dados observados e atividades práticas abordadas que o lúdico se faz necessário principalmente na educação infantil. 
Contudo, desse modo, é valido explanarmos que a escola desempenha um papel o qual vai para além dos princípios pedagógicos. O hábito alimentar se faz presente no cotidiano dos nossos dias e das nossas atividades, compreendendo que as crianças passam um expressivo período de tempo nas instituições de ensino, o hábito alimentar a princípio, se efetiva em âmbitos escolares.

A Educação é um importante meio de mudança social, onde os alunos representam papel fundamental na mudança de consciência e na prática de novos hábitos. Nesse sentido, torna-se necessário que a sociedade em sua totalidade desempenhe também hábitos alimentares saudáveis, os quais façam presente no âmbito família, pois perpassar essas práticas é de fato contribuir para uma alimentação eficaz.

Ao analisar esses desenvolvimentos, os profissionais da educação puderam aprimorar os seus conhecimentos quanto à eficácia da inserção da ludicidade na Educação Infantil, além disso, tem como finalidade que novas políticas em sala de aula sejam traçadas para atingir o objetivo de influenciar positivamente a alimentação saudável das crianças, tendo em vista que através de estudos realizados em sala de aula a alimentação saudável torna-se mais atraente quando práticas lúdicas são relacionadas aos alimentos, essa junção é primordial para na Educação Infantil.

Portanto, entende-se que avaliar a influência da inserção da Educação na mudança do perfil social dos alunos quanto a questões relacionadas à socialização é de extrema importância na questão dos bons hábitos alimentares, pois trabalharmos a questão da alimentação assim como a ludicidade é entendermos que, a criança faz parte desse contexto dinâmico, na medida em que inserimos os alunos nessas aulas, teremos um resultado eficaz.

Através desse arranjo, é perceptível que a docência na Educação passou e ainda perpassa por grandes enfrentamentos, as dificuldades que a profissão vem enfrentando permeiam para além do âmbito escolar, conhecer a realidade enfrentada dos nossos alunos é um dos nossos desafios no cotidiano, tendo em vista que a aprendizagem das crianças só se efetiva estando em consonância com o grupo familiar. Dessa forma, o professor desde então busca estratégias de ensino e aprendizagem as quais estejam diretamente vinculadas a família das crianças.

É por meio da instrumentalidade profissional que ocorre o acompanhamento teórico e prático do profissional especializado, considerando o projeto ético político, é perceptível visualizar a importância dessa profissão enquanto categoria profissional. E de fato, o reconhecimento dessa categoria profissional ainda hoje na contemporaneidade classifica-se como desvalorizada, pelos órgãos públicos, privados, assim como pelas famílias do alunado.

Atuar na Educação é buscar os principais registros de concretização das leis dentre outras questões relacionadas à efetivação das políticas nos referidos serviços, bem como fortalecer os vínculos familiares, comunitários, promovendo a inclusão das famílias e cidadãos nas referidas políticas públicas, no âmbito escolar, e em todo o contexto que possibilite a promoção do desenvolvimento de suas potencialidades.

Contudo, esse trabalho, foi construído sobre estruturas pilares que o sustenta, pois é fundamental para nossa formação, assim como o planejamento, que é fundamental para a atuação do professor no cotidiano da sala de aula, ele dará a importância devida para o desenvolvimento da aula, proporcionando um ensino o qual busque a excelência na organização, observação e regência.

Além disso, A prática de hábitos alimentares saudáveis, que também envolvem a prática de exercício físico regulares, deve ser estudada e incentivada em âmbito escolar, para que assim as crianças orientem seus familiares para adotar essas medidas, evitando doença e promovendo saúde (Sousa, 2014).

A nutrição é um fator essencial na preservação da saúde. No entanto Lima (2008) refere que essa conscientização deve ser realizada com um incentivo a promoção de saude, isto é, por meio da educação nutricional. Desta forma, a sociedade necessita de informações para obter uma boa alimentação, par alcançar uma boa qualidade de vida (Sousa, 2014). 
Em crianças de 2 e 3 anos de idade deve-se ter maior cuidado em relação a alimentação, é nesta faixa etária que ocorre a inclusão de novos hábitos alimentares, devido o conhecimento de novos sabores, texturas e cores. A criança desta faixa etária estaria sobre influência dos membros familiares, que lhes oferecem para consumo (Sousa, 2014).

Para um desenvolvimento corporal saudável, a criança deve consumir uma porcentagem necessária de alimentos, o apetite nesta faixa etária é irrelugar, haveras dias em que ira aceita o alimento, e outro o recusara. Desta forma Philippi (2003) recomenda que os alimentos devem ser preparados e introduzidos na alimentação da criança, conforme seu interesse para assim contribuir na aprendizagem do consumo de uma dieta equilibrada. (Sousa, 2014)

Portanto, o planejamento tornou-se a ferramenta principal para o desenvolvimento do trabalho profissional, é a partir dele que podemos estruturar todos os conhecimentos no âmbito educacional.

Desse modo, o planejamento Educacional tornou-se a ferramenta principal para o desenvolvimento do trabalho profissional, buscando cada dia mais objetivos e mecanismos os quais influenciam de forma positiva a relação não só do professor-aluno, bem como o acompanhamento de estratégias de intervenção nas análises pedagógicas a qual a Escola está inserida.

Compreender a relevância da estruturação desse Planejamento é sem dúvidas, compreender como se dão as práticas pedagógicas, e como elas são inseridas no âmbito educacional, pois ao analisar esse projeto com convicção, provavelmente estaremos caminhando para resultados colocados em ação, ou seja, planejamentos concretos.

Contudo, está pesquisa será de grande importância, pois permitirá que profissionais como o psicólogo e o professor possam aprimorar os seus conhecimentos quanto à eficácia da inserção da ludicidade na Educação Infantil, além disso, servirá para que novas políticas em sala de aula sejam traçadas para atingir o objetivo de influenciar positivamente a alimentação saudável das crianças.

Desse modo, é preciso entender qual correlação existente entre o aprendizado de crianças e as práticas lúdicas relacionadas à educação alimentar, pois analisar a implementação de práticas lúdicas nas salas de aula e o seu impacto na alimentação de crianças da educação infantil e avaliar a influência da inserção da Educação na mudança do perfil social dos alunos quanto a questões relacionadas à socialização e importância de bons hábitos alimentares.

A infância é uma fase que passa por período de intensas modificações, que vão desde as transformações fisiológicas do corpo até as mudanças psicológicas.

Em toda fase da vida, o ser humano está sempre descobrindo e adquirindo conhecimentos novos através do contato com seus semelhantes no ambiente social. Segundo Piaget (1975) o conhecimento perpassa por constantes transformações, o que permite o ser humano criar, aprimorar e concretizar seus pensamentos e habilidades mentais.

Diante disso, o referido autor ainda defende a teoria a qual aborda o conhecimento como uma via inacabada, podendo sempre passando por transformações sócias.

Esse arranjo nos possibilita analisarmos o quanto é imprescindível enfatizar a importância dada à educação às crianças, inserir a criança no âmbito escolar é desenvolver aprendizagem infantil, tendo em vista que essa é uma fase em que as crianças vivenciam uma gama de adaptações ao meio físico e social, é ainda nesse momento que acontece o rompimento do laço familiar para iniciar uma nova experiência, pois a criança passar boa parte do tempo na escola na companhia de educadores.

Contudo, esse convívio proporciona aos pequenos aprendizes o desenvolvimento da capacidade de socialização, segurança, autoconfiança, da autonomia, dos aspectos cognitivo, biológico e sócio-afetivo (Silva, 2014). 
Para além disso, na educação infantil deve-se observar as habilidades cognitivas, ações e expressões comportamental das crianças. Em decorrência disso, vale salientar a importância da alimentação saudável na infância, a qual vem sendo discutido a um longo período. Desse modo,

A preocupação em torno da alimentação faz parte da história da humanidade. As lutas pela alimentação e sobrevivência são indissociáveis, desde os primórdios do tempo. No início do século XX, iniciou o que se pode chamar de compreensão mais global sobre o significado da Segurança Alimentar. Após a I Guerra os países perceberam que a provisão de alimentos alcançara uma importância de segurança nacional ultrapassando as fronteiras internas e atingindo uma preocupação internacional. (Jesus, 2016, p. 20).

Explicitando esse ocorrido, a atenção voltada para a alimentação, se faz presente por meio do Direito Humano e o bem estar vida, é através da efetivação das políticas públicas e sociais, que o debate sobre alimentação adequada e saudável passou pelo processo de formulação, o qual percorre até hoje a um planejamento alimentar saudável em todos os âmbitos sociais.

Todavia, o mundo globalizado de hoje, onde o tempo é considerado um recurso, extingue alguns hábitos excessivamente demorados, por outros mais rápidos, tudo para economizar tempo e volta ao trabalho.

Dentre esses hábitos a prática de alimentos saudável muitas vezes é substituída por alimentos feitos em lanchonetes, fast-foods ou comidas congeladas e industrializadas (Sousa, 2014).

Tendo em vista que a nutrição é crucial para preservação da saúde, principalmente em crianças de 2 e 3 anos, deve-se ter uma atenção mais voltadas para estas em relação a alimentação, pois, é nesta faixa etária que as mesmas despertam novos hábitos alimentares.

Esses interesses se propagam de uma maior forma nessa faixa etária, devido essas crianças terem o primeiro acesso aos alimentos, os quais por sua vez oportunizam novos sabores, texturas e cores. Diante disso, Jesus (2016, p. 24) ressalva:

É uma fase que se caracteriza por um período em que ocorrem as maiores e mais rápidas mudanças de todo o ciclo de vida, tanto do ponto de vista físico (crescimento) como psíquico e cognitivo (desenvolvimento) e principalmente no seu período inicial, ou seja, nos primeiros dois anos de vida. Esta característica torna esta fase da vida a de maior risco para a saúde do indivíduo, necessitando por isso, cuidados especiais na atenção às suas necessidades básicas.

Por meio dessas observações, fica explicito o quanto é valioso o acesso à educação alimentar, o bem-estar das crianças parte principalmente dos anos iniciais os quais estão sendo desenvolvidos seus sentidos e compressão acerca da alimentação no âmbito familiar assim como escolar.

As práticas alimentares e hábitos saudáveis, são constituídos pelos indivíduos a parti das relações sociais que estabelecem em diferentes espaços de convivência. Na infância, além da família, o ambiente escolar é um local favorável para o desenvolvimento de ações para a promoção de práticas alimentares saudáveis por ser um espaço de socialização (Silva \& Boccaletto).

A Educação é um importante meio de mudança social, onde os alunos representam papel fundamental na mudança de consciência e na prática de novos hábitos. A sociedade passa por mudanças de valores onde o imediato e individual supera o durável e coletivo.

$\mathrm{O}$ individualismo presente entre os alunos é algo evidente. A rotina acelerada da população fez com que os maus hábitos alimentares invadissem a dieta familiar, e alimentos como frutas, legumes e hortaliças fossem substituídos por industrializados.

O conceito de atividades lúdicas está relacionado com o ludismo, que por sua vez está direcionado a jogos os quais tem como finalidade a desenvoltura pelo ato de brincar. Desse modo, 
O lúdico tem sua origem na palavra latina "ludus" que quer dizer "jogo". Se achasse confinado a sua origem, o termo lúdico estaria se referindo apenas ao jogar, ao brincar, ao movimento espontâneo. O lúdico passou a ser reconhecido como traço essencial de psicofisiologia do comportamento humano. De modo que a definição deixou de ser o simples sinônimo de jogo. As implicações da necessidade lúdica extrapolaram as demarcações do brincar espontâneo (Ferreira \& Silva Reschke, [s/d], p.3).

Diante do exposto, entendemos que as atividades lúdicas estão presentes em todas as fases e classes sociais, crianças de várias idades além de brincar, expressam suas habilidades por meio da ludicidade. Assim como, promove a aprendizagem ea qual estimula o desenvolvimento intelectual e social da criança, ou seja, uma aprendizagem eficaz e completa.

Para Piaget (1975) e Winnicott (1975), definições como jogo, brinquedo e brincadeira são formadas ao longo de nossas vivencias. É a forma que cada um utiliza nomear o brincar. Contudo, tanto a palavra jogo quanto a palavra brincadeira podem ser sinônimos de divertimento. (Dallabona \& Mendes, 2004)

O brincar é determinado por duas características: criação de situação imaginária e comportamento regrado. De acordo com Vygotsky, reconhecer a existência de situação imaginária na brincadeira foi frequentemente associado a determinado tipo de jogo.

Em conformidade, qualificar qualquer jogo ou brincadeira pela atuação dos processos imaginários significa reconhecer o vínculo existente entre motivação lúdica e desenvolvimento do pensamento simbólico. (Pimentel, 2008)

Desse modo, de fato, a ludicidade contribui para o desenvolvimento íntegro, porque nela surgi um campo de aprendizagem propício à formação de imagens, à conduta auto-regulada, à criação de soluções e avanços nos processos de significação. Na brincadeira são propostas as ações coordenadas e organizadas, dirigidas a um fim e, por isso, antecipatórias, favorecendo um funcionamento intelectual que leva à consolidação do pensamento abstrato.

A força motora da ludicidade, o que a faz tão importante no complexo processo de apropriação de conhecimentos é a combinação incoerente de liberdade e controle. Ao mesmo tempo em que os horizontes se ampliam conforme os rumos da imaginação, o cenário lúdico se emoldura segundo limites que os próprios jogadores se impõem, subordinando às regras que conduzem a atividade lúdica. (Pimentel, 2008). Destarte,

As escolas estão sendo cobradas a trabalhar o lúdico, pois a BNCC valoriza muito o lúdico e a maior parte das escolas já estão adaptando essa modalidade e os professores tem que buscar sempre está por dentro das novidades, alguns sentem dificuldade em desenvolver as aulas, mas aprendem com facilidade, com o uso da tecnologia tudo fica mais fácil. Sabe-se que com o uso da mesma é possível realizar diversas atividades do cotidiano escolar, mas não pode deixar de lado o lúdico, principalmente na educação infantil, pois o lúdico desperta vários aspectos positivos nas crianças, a construção de classificações, elaboração de sequências lógicas, desenvolvimento do psicomotor, a afetividade e ampliação de conceitos das várias áreas da ciência. (Maia, 2020, p. 3).

As aulas desenvolvidas em sala de aula têm o lúdico como um dos métodos para aprendizagem, são aulas voltadas aos interesses do aluno sem perder seu objetivo, jogos e brincadeiras, segundo Oliveira, (1985, p. 74), é “(...) um recurso metodológico capaz de propiciar uma aprendizagem espontânea e natural.

Estimula a critica, a criatividade, a socialização, sendo, portanto, reconhecidos como uma atividade mais significativa - senão a mais significativa - pelo seu conteúdo pedagógico.

Desse modo, torna-se crucial a consolidação da ludicidade, educação infantil e hábitos alimentares, esse arranjo nos possibilita analisarmos a importância do desenvolvimento amplo das crianças em sua totalidade.

A educação lúdica contribui e influencia na formação da criança, possibilitando um crescimento sadio, um enriquecimento permanente, integrando-se ao mais alto espírito democrático enquanto investe em uma produção séria 
do conhecimento. A sua prática exige a participação franca, criativa, livre, crítica, promovendo a interação social e tendo em vista o forte compromisso de transformação e modificação do meio. (Almeida, 2008, p. 41).

Ou seja, a ludicidade é um fator crucial para o conhecimento da criança, pois o mesmo que a criança desenvolva possibilita interação social, crescimento cognitivo, motor e social.

Diante de todo contexto colocado no decorrer do referido relatório, no Brasil, as lutas continuam para que se efetivem uma Política que de fato corroborasse para o desenvolvimento educacional.

Atuar na Educação é buscar os principais registros de concretização das leis dentre outras questões relacionadas à efetivação das políticas nos referidos serviços, bem como fortalecer os vínculos familiares, comunitários, promovendo a inclusão das famílias e cidadãos nas referidas políticas públicas, no âmbito escolar, e em todo o contexto que possibilite a promoção do desenvolvimento de suas potencialidades. Trazendo também, a importância da a inserção da ludicidade como recurso para uma alimentação saudável na educação infantil.

\section{Considerações Finais}

Diante do estudo, foi possível verificar que O projeto contribuiu na construção crítica e reflexiva sobre o material didático, onde percebeu-se a importância do livro para a formação dos discentes, posto que o mesmo tem como função trazer, em uma linguagem clara e accessível, os conteúdos curriculares em interação com as necessidades sociais de cada época. Assim, o conhecimento e experiências compartilhadas sobre os alimentos e convívio social foram válidos, uma vez que o aprendizado foi mútuo, professor-aluno, aluno-professor.

Uma alimentação saudável e equilibrada, promovendo o consumo de frutas, desde o momento em que se começa a ingerir alimentos a criança vai desenvolvendo hábitos saudáveis que possam levar para toda sua vida.

Foi de grande importância esse estágio para minha formação acadêmica, pois conheci e vivenciei uma nova realidade, desconhecida por mim. Assim como consegui por em prática tudo que planejei, diante ao nervosismo por alguns momentos, alcancei meus objetivos planejados antes do estágio. Mesmo diante as dificuldades propostas pelos alunos e alguns empecilhos surgidos ao longo do estágio, consegui decifrar todos e obter bons resultados.

\section{Referências}

Albuquerque, J. P. S., dos Santos, A. M. A., de Araujo, B. J., Delgado, G. D. M., dos Santos Gomes, D. G., Lins, H. D. A. A., ... \& Guerra, A. Q. S. Orientações sobre alimentação saudável e prevenção da obesidade infantil nas escolas públicas em João Pessoa--PB. Diálogos da Extensão, 74.

Almeida, M. S. de et al. (2021). O impacto da má alimentação infantil à longo prazo na saúde do adulto. Revista Eletrônica Acervo Científico, 39, e9272e9272.

Almeida, P. N. de. (2008). Educação lúdica: técnicas e jogos pedagógicos. São Paulo, SP: Loyola.

Armesto, L. M., \& Bispo, P. P. G. (2022). O papel da escola na sociedade contemporânea: formação baseada em valores e o ideário dos saberes. RECIMA21Revista Científica Multidisciplinar-ISSN 2675-6218, 3(1), e311069-e311069.

Brum, M. M. D. (2021). O excesso de peso na infância e adolescência e o risco para diabetes tipo II: uma revisão de produção científica presente na Biblioteca Virtual de Saúde, 2016-2021.

Gutierrez, S. M., \& De Sales, J. C. (2021). Fatores que desencadeiam a obesidade infantil e a importância do papel do nutricionista em âmbito escolar. Brazilian Journal of Development, 7(10), 97539-97550.

Castro, M. A. V. de, Lima, G. C. de, \& Araujo, G. P. B. (2021). Educação alimentar e nutricional no combate à obesidade infantil: visões do Brasil e do mundo. Revista da Associação Brasileira de Nutrição-RASBRAN, 12(2), 167-183.

Ferraz, M. D. A. (2021). O papel do Estado na prevenção da obesidade infantil: enfoque em medidas para desestimular o consumo de alimentos não saudáveis (Doctoral dissertation, Universidade de São Paulo).

Ferreira, J. de F., Silva, J. A. da., \& Reschke, M. J. D. (2017). A importância do lúdico no processo de aprendizagem. https://www2.faccat.br/portal/sites/default/files/A\%20IMPORTANCIA\%20DO\%20LUDICO\%20NO\%20PROCESSO. 
Research, Society and Development, v. 11, n. 2, e32811224056, 2022

(CC BY 4.0) | ISSN 2525-3409 | DOI: http://dx.doi.org/10.33448/rsd-v11i1.24056

Jesus, A. (2016). Alimentação saudável na escola: promovendo a saúde e construindo ações de segurança alimentar. belo horizonte - Minas Gerais.

Maia, M. dos N. F. da S. (2019). A importância da ludicidade na educação infantiL. In: Anais Educação e Formação Continuada na Contemporaneidade. Anais...Natal(RN) Evento on-line - Amplamente Cursos. https//www.even3.com.br/anais/Amplamentecursos/237716-A-IMPORTANCIA-DALUDICIDADE-NA-EDUCACAO-INFANTIL

Marques, D. S. (2021). Estratégias utilizadas por equipes pedagógicas de Educação Infantil diante da identificação de dificuldades cognitivas e emocionais apresentadas pelas crianças em seu processo de desenvolvimento.

Neves Ramos, D. B das. (2021). Estratégias para prevenção e controle da obesidade infantil nas cidades brasileiras. Revista Multidisciplinar em Saúde, 2(4), 271-271.

Pereira, S. (2021). Práticas de uma escola de Educação Infantil. Equatorial-Revista do Programa de Pós-Graduação em Antropologia Social, 8(15), 1-23.

Santos Silva, D. F. dos et al. (2021). Educação alimentar e nutricional na infância: aplicação de estratégias em incentivo a alimentação saudável. Revista Conexão UEPG, 17(1), 1-12.

Santos, A. B. M. V. dos, et al. (2021). Caminhos para articulação da Educação Alimentar e Nutricional com o currículo escolar: relato de experiência no contexto do ensino fundamental. DEMETRA: Alimentação, Nutrição \& Saúde, 16, 56719.

Silva, V. da S. da, \& Costa de Bom, F. (2016). O planejamento nas aulas de educação física na educação infantil em escolas da rede pública e privada do município. o planejamento nas aulas de educação física na educação infantil em escolas da rede pública e privada do município de morro da fumaça - sc, n. 17 , p. $1 / 17$

Souza Mariano, L. P. T. de., Silva, P. F. da, Silva, T. S. A. da, Silva, F. O. da., \& Lemos, A. C. G. (2022). Educação alimentar e nutricional aplicada à um grupo de idosos participantes de um programa social, por meio de atividades lúdicas e palestras. Revista Saúde UniToledo, 5(1).

Tavares, C. P., Cândida, M. M., \& CARNEIRO, P. (2021). Obesidade infantil: a educação física como estratégia de prevenção no âmbito escolar. Anais do Fórum de Iniciação Científica Do UNIFUNEC, 12(12).

Torres, L. C., de Abreu, A. P. N., Costa, F. A., \& da Silva, P. A. Projeto horta escola e sua atuação em campo grande-ms: atuação, desafios e percepções (2021). Cidadania em Ação: Revista de Extensão e Cultura, 5(2), 133-144. 